\title{
CHEMICAL REACTIVITY, DIPOLE MOMENT AND FIRST HYPERPOLARIZABILITY OF ARISTOLOCHIC ACID I
}

\section{Bhawani Datt Joshi}

Journal of Institute of Science and Technology

Volume 21, Issue 1, August 2016

ISSN: 2469-9062 (print), 2467-9240(e)

Editors:

Prof. Dr. Kumar Sapkota

Prof. Dr. Armila Rajbhandari

Assoc. Prof. Dr. Gopi Chandra Kaphle

JIST, 21 (1), 1-9 (2016)

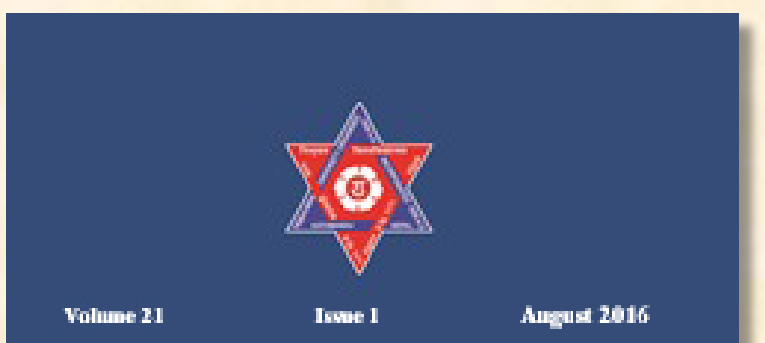

JOURNAL OF INSTITUTE OF SCIENCE AND TECHNOLOGY
Published by

Institute of Seience and Teehnology

Tribhuvan University

Kirtipur, Kathmanda, Nepal

Published by:

Institute of Science and Technology

Tribhuvan University

Kirtipur, Kathmandu, Nepal 


\title{
CHEMICAL REACTIVITY, DIPOLE MOMENT AND FIRST HYPERPOLARIZABILITY OF ARISTOLOCHIC ACID I
}

\author{
Bhawani Datt Joshi ${ }^{1,2}$ \\ ${ }^{I}$ Department of Physics, Siddhanath Sc. Campus, Tribhuvan University, Mahendranagar, Nepal \\ ${ }^{2}$ Departamento de Física, Universidade Federal do Ceará, Fortaleza, CE, Brazil \\ Corresponding email: pbdjoshi@gmail.com
}

\begin{abstract}
Aristolochic acids (AAs) have been used in the treatment of oedema in Chinese herb medicine since long ago. In this paper, molecular electrostatic potential, chemical reactivity and non linear optical properties of aristolochic acid I (AA I) have been analyzed using density functional theory employing 6-311++G(d,p) basis set. The chemical reactivity of the molecule has been explained with the help of chemical reactivity descriptors, molar refractivity and the molecular electrostatic potential surface (ESP). The calculated dipole moment and first order hyperpolarizability show that the molecule possesses non-linear optical property.
\end{abstract}

Keywords: AA I, DFT, Chemical reactivity, MEP, Hyperpolarizability

\section{INTRODUCTION}

Plant based natural products cover a major sector of the medicinal field. As such, focus on plant research has increased all over the world. Herbs containing aristolochic acids (AAs), a family of nitrophenanthrene carboxylic acids (Aristolochiaceae), have an increasing global medical attention (Cronin et al. 2002). Mixture of aristolochic acid I (AA I) and aristolochic acid II (AA II) is a principal chemical constituent of Aristolochia species (Pailer et al. 1995). Herbal drugs derived from Aristolochia spp. have been known before middle age in the treatment of snake bites (Rosenmund \& Reichstein 1943). Their roots have different biological functions such as; treatment of stomach-ache, hypertension relief, leukocyte enhancement, rheumatism relief, edema therapy, toothache, gout, eczema etc (Kupchan \& Doscoth 1962; Mizuno et al. 1991; Tang and Eisenbrand 1992; Bensky et al. 1993). Thirugnanasampandan et al. 2008 reported the antioxidant properties of different Aristolochia spp. However, AAs are found to have nephrotoxic and carcinogenic properties, and may cause renal failure in human (Zheng et al. 2000; Li et al. 2001; Balachandran et al. 2005; Cosyns 2003; Attaluri et al. 2010; Das 2016).

Alkaloids have very complex structure and occupy unique place in the field of natural products. Their structural elucidation, synthesis and the determination of constituents is a big challenging problem. Vibrational spectroscopy is a valuable method for studying electronic structures and dynamical behavior of the alkaloids (Mishra et al. 2014). Raman and IR spectroscopic methods are the traditional methods of vibrational analysis, and particularly useful for non-destructive characterization of substances (Chamers 2002). In the recent years, there has been increasing interest in the application of $a b$ initio calculations to alkaloids as the calculations provide additional interpretation of the vibrational spectroscopic data as demonstrated in our earlier studies (Joshi et al. 2014; Mishra et al. 2014). In this communication, the chemical reactivity and non linear optical properties have been calculated as an aid to our previous publication (Joshi et al. 2013). The calculations have been made by the density functional theory (DFT) (Hohenberg \& Kohn 1964) using Gaussian 09 program (Frisch et al. 2009) employing $6-311++\mathrm{G}(\mathrm{d}, \mathrm{p})$ basis set. The chemical structure of AA I is shown in the Fig. 1.

\section{MATERIALS AND METHODS}

\section{Computational method}

Using the standard parameters, geometry optimization has been made as the first task by DFT (Hohenberg \& Kohn 1964) method, without any constraints of molecular symmetry. The optimized 
parameters have been used for all the other calculations. The calculations were carried in the personal system using Gaussian 09 program (Frisch et al. 2009) in the frame work of closed-shell Becke's three parameters (Lee-Yang-Parr hybrid exchange correlation) functional (B3LYP) (Becke 1993, Lee et al. 1988, Perdew \& Wang 1992) employing 6-311++G(d,p) basis set. The optimized ground state structure was confirmed to be a minimum energy and shown in the Fig. 2. The chemical reactivity descriptors, which are helpful to explain the stability and reactivity of the molecule has been calculated on the basis of Koopmans's theorem (Parr \& Yang 1998) using B3LYP/6$311++\mathrm{G}(\mathrm{d}, \mathrm{p})$. Visualization and confirmation of the calculated data were done by using the program CHEMCRAFT (Zhurko \& Zhurko 2005).<smiles>COc1cccc2c1cc([N+](=O)[O-])c1c(C(=O)O)cc3c(c12)OCO3</smiles>

Fig.1. Chemical structure of AA I.

\section{RESULTS AND DISCUSSION}

\section{Chemical reactivity}

The chemical reactivity of a molecule can be explained in three ways: (i) by MEP (molecular electrostatic potential surface) mapping (ii) global and local reactivity descriptors, and (iii) the molar refractivity (MR).

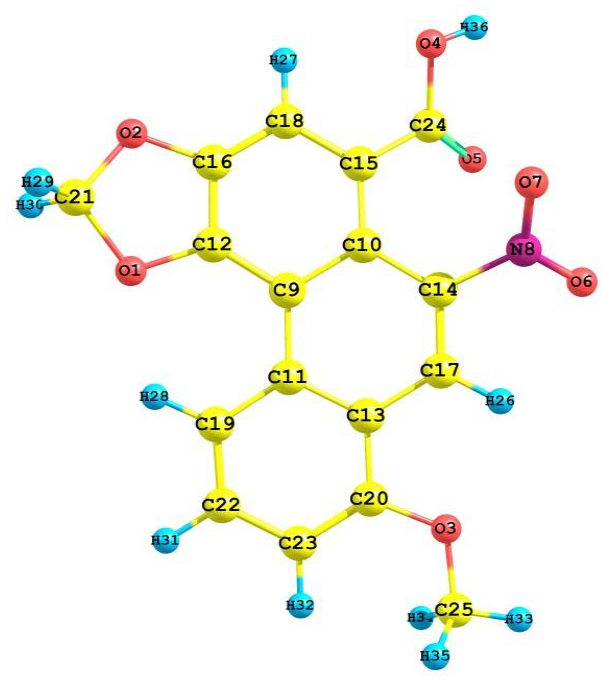

Fig.2. Optimized structure of AAI.

Molecular electrostatic potential surface (MEP): The MEP is a visualization method to understand the relative polarity, reactivity, size and the structureactivity of a molecule including biomolecules and drugs (Chidangil et al. 1998). In such surfaces, the negative electrostatic potential corresponds to attraction of the protons by the concentrated electron density in the molecule (from lone pair, pi-bonds etc.). Similarly, positive electrostatic potential corresponds to the repulsion of the proton by the atomic nuclei in the region where low electron density exists and the nuclear charge is incompletely shielded. The MEP mapping together with electron density (ED) and electrostatic potential surface (ESP) of AA I were given in our previous publication (Joshi et al. 2013). In a surface, the potential increases in the color order red < orange < yellow < green < blue. Fig. 3 shows the distribution of Mulliken charges and natural charges in the molecule whereas a comparison of Mulliken charges and natural charges obtained by different basis sets is listed in the Table 1 .

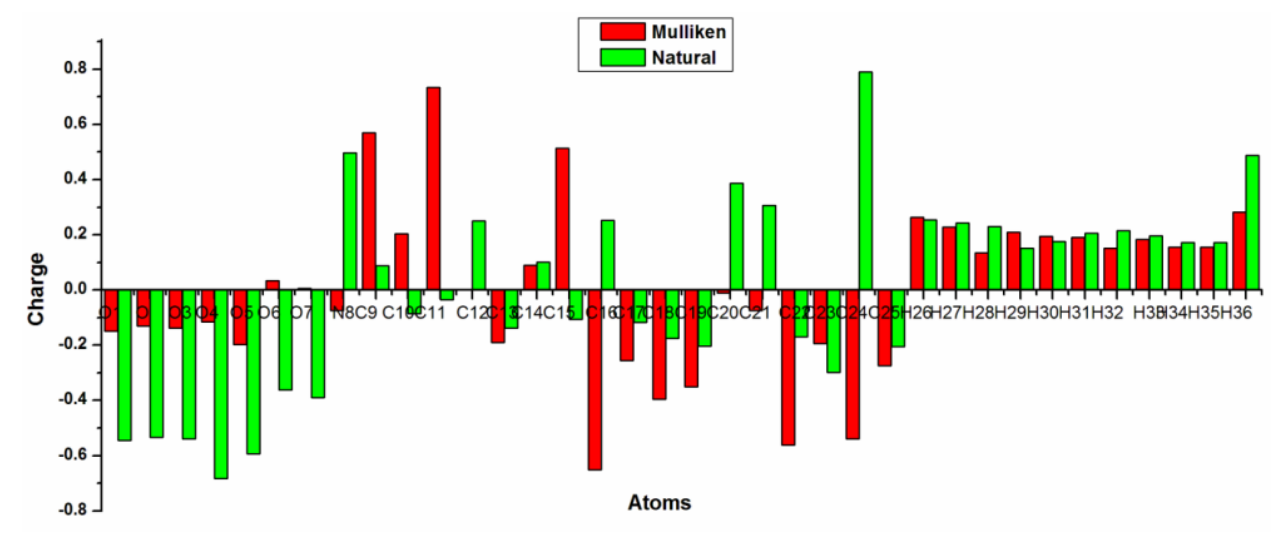

Fig. 3. Plot of Mulliken charges and Natural charges obtained by B3LYP/6-311++G(d,p). 
Table 1. Comparison between Mulliken charges and Natural charges obtained by B3LYP.

\begin{tabular}{|c|c|c|c|c|c|c|}
\hline \multirow[t]{2}{*}{ Atoms } & \multicolumn{3}{|c|}{ Mulliken charges (e.s.u.) } & \multicolumn{3}{|c|}{ Natural charges (e.s.u.) } \\
\hline & $6-31 \mathrm{G}$ & $6-311 G(d, p)$ & $6-311++\mathrm{G}(\mathrm{d}, \mathrm{p})$ & $6-31 G$ & $6-311 G(d, p)$ & $6-311++G(d, p)$ \\
\hline $\mathrm{O} 1$ & -0.553889 & -0.364277 & -0.148084 & -0.52820 & -0.54145 & -0.54378 \\
\hline $\mathrm{O} 2$ & -0.538214 & -0.340688 & -0.131092 & -0.51548 & -0.52447 & -0.53301 \\
\hline $\mathrm{O} 3$ & -0.519301 & -0.353728 & -0.137756 & -0.51470 & -0.52630 & -0.53966 \\
\hline $\mathrm{O} 4$ & -0.488296 & -0.322872 & -0.115072 & -0.69602 & -0.68833 & -0.68305 \\
\hline $\mathrm{O} 5$ & -0.475640 & -0.334223 & -0.197542 & -0.56936 & -0.59525 & -0.59412 \\
\hline O6 & -0.373744 & -0.247574 & 0.033987 & -0.35045 & -0.36809 & -0.36154 \\
\hline $\mathrm{O} 7$ & -0.398553 & -0.276055 & 0.005448 & -0.37538 & -0.38906 & -0.39037 \\
\hline N8 & 0.369272 & 0.159421 & -0.074267 & 0.48666 & 0.52178 & 0.49671 \\
\hline C9 & 0.014524 & -0.058968 & 0.570488 & -0.05574 & -0.06229 & 0.08893 \\
\hline $\mathrm{C} 10$ & 0.103679 & 0.111570 & 0.203150 & -0.02709 & -0.02893 & -0.08512 \\
\hline $\mathrm{C} 11$ & 0.093333 & 0.020729 & 0.733601 & -0.01421 & -0.00888 & -0.03411 \\
\hline $\mathrm{C} 12$ & 0.237359 & 0.077054 & -0.000386 & 0.27848 & 0.29838 & 0.25043 \\
\hline $\mathrm{C} 13$ & 0.012557 & -0.150005 & -0.190015 & -0.08802 & -0.09364 & -0.13762 \\
\hline $\mathrm{C} 14$ & 0.167990 & 0.070922 & 0.090220 & 0.09265 & 0.10279 & 0.10065 \\
\hline $\mathrm{C} 15$ & 0.017303 & -0.075092 & 0.513649 & -0.12112 & -0.12469 & -0.10558 \\
\hline $\mathrm{C} 16$ & 0.330580 & 0.189616 & -0.651163 & 0.24361 & 0.26639 & 0.25292 \\
\hline $\mathrm{C} 17$ & -0.096866 & 0.093222 & -0.254518 & -0.17170 & -0.14288 & -0.11780 \\
\hline $\mathrm{C} 18$ & -0.133807 & -0.002244 & -0.395913 & -0.22496 & -0.20032 & -0.17532 \\
\hline C19 & -0.130233 & -0.029274 & -0.350947 & -0.24397 & -0.21510 & -0.20279 \\
\hline $\mathrm{C} 20$ & 0.318066 & 0.199718 & -0.010963 & 0.34423 & 0.36943 & 0.38610 \\
\hline $\mathrm{C} 21$ & 0.289326 & 0.174379 & -0.074135 & 0.17547 & 0.31780 & 0.30682 \\
\hline $\mathrm{C} 22$ & -0.103199 & -0.092125 & -0.561252 & -0.20649 & -0.15646 & -0.16978 \\
\hline $\mathrm{C} 23$ & -0.132462 & -0.101236 & -0.193857 & -0.32317 & -0.29494 & -0.29866 \\
\hline $\mathrm{C} 24$ & 0.528521 & 0.331738 & -0.539927 & 0.77191 & 0.82079 & 0.79036 \\
\hline $\mathrm{C} 25$ & -0.083123 & -0.132033 & -0.274446 & -0.35254 & -0.19504 & -0.20427 \\
\hline $\mathrm{H} 26$ & 0.151888 & 0.133533 & 0.264118 & 0.29317 & 0.25067 & 0.25420 \\
\hline $\mathrm{H} 27$ & 0.134594 & 0.121709 & 0.227601 & 0.28475 & 0.24062 & 0.24232 \\
\hline
\end{tabular}




$\begin{array}{lllllll}\text { H28 } & 0.116816 & 0.111899 & 0.134226 & 0.27025 & 0.22801 & 0.23000 \\ \text { H29 } & 0.123653 & 0.122977 & 0.210389 & 0.21366 & 0.14663 & 0.15173 \\ \text { H30 } & 0.131733 & 0.131284 & 0.195307 & 0.23969 & 0.16912 & 0.17525 \\ \text { H31 } & 0.093661 & 0.096751 & 0.191062 & 0.24900 & 0.20347 & 0.20669 \\ \text { H32 } & 0.092427 & 0.106959 & 0.152074 & 0.24956 & 0.21207 & 0.21460 \\ \text { H33 } & 0.135005 & 0.137823 & 0.184332 & 0.24893 & 0.19052 & 0.19686 \\ \text { H34 } & 0.118847 & 0.116404 & 0.154732 & 0.21768 & 0.16797 & 0.17305 \\ \text { H35 } & 0.118125 & 0.115942 & 0.155489 & 0.21681 & 0.16740 & 0.17251 \\ \text { H36 } & 0.328067 & 0.256744 & 0.281461 & 0.50206 & 0.48228 & 0.48706\end{array}$

Global reactivity descriptors: The global reactivity descriptors; chemical potential $(\mu)$, hardness $(\eta)$, softness $(s)$, electronegativity $(\chi)$ and electrophilicity index $(\omega)$ to explore reactivity, has been calculated using DFT efficiently (Geerling et al. 2003, Chattaraj \& Giri 2007). The chemical potential, measure of the tendency of electron donation from the equilibrium position is given by:

$\mu=\frac{1}{2}\left(E_{\text {LUMO }}+E_{\text {Hомо }}\right)=-\chi$

The global hardness ( $\eta$ ), that indicates the resistance to transfer the charge and the softness $(s)$, that measures the charge transfer properties are defined by:

$\eta=\frac{1}{2}\left(E_{\text {LUMO }}-E_{\text {НОMO }}\right)$

$s=1 / 2 \eta$

$E_{\text {Номо }}$ and $E_{\text {Номо }}$ in equations (1) and (2) are the energies of frontier molecular orbitals; the highest occupied molecular orbital (HOMO) and lowest unoccupied molecular orbital (LUMO), respectively.

Similarly, the electrophilicity index $(\omega)$ which represents the property of molecule to accept the electron from the surroundings can be calculated as:

$\omega=\frac{1}{2}\left(\frac{\mu^{2}}{\eta}\right)$

Further, a new reactivity index $(\Delta \mathrm{N})$, which indicates the stabilization in energy when the system acquires additional charge from the environment up to the saturation, was calculated as:

$\Delta \mathrm{N}=-\frac{\mu}{2 \eta}$

The calculated values of these indices are listed in the Table 2. The calculated high value of electrophilicity index $(\omega)$ shows that the molecule behaves as a strong electrophile.

Table 2. Calculated $E_{\text {Hомо }}, E_{\mathrm{Lumo}}$, energy band gap $(\Delta E)$, electronegativity $(\chi)$, chemical potential $(\mu)$, global hardness $(\eta)$, global softness $(S)$, global electrophilicity index $(\omega)$ and additional electronic charge $\left(\Delta N_{\text {max }}\right)$ (in eV) for AA I, using B3LYP/6-311++G(d,p).

\begin{tabular}{llllllll}
\hline$E_{\text {НОмо }}$ & $E_{\text {LUMO }}$ & $\Delta E$ & $\mu$ & $\eta$ & $S$ & $\omega$ & $\Delta \mathrm{N}_{\max }$ \\
\hline-6.216580 & -2.690827 & -3.525754 & -4.453703 & 1.762877 & 0.283627 & 5.625880 & 2.526383 \\
\hline
\end{tabular}

Local reactivity descriptors: The global chemical reactivity descriptors forecast the reactivity of the molecular system but can't elucidate the site. Therefore, the local reactivity descriptors, which reveal the reactivity sites, have been calculated. Applying Hirshfeld population method, Fukui functions $\left(f_{k}^{+}, f_{k}^{-}, f_{k}^{o}\right)$ (Parr et al. 1999, Geerlings et al. 2003) were calculated using B3LYP/6$311++\mathrm{G}(\mathrm{d}, \mathrm{p})$ level of theory. The sites with higher values of Fukui function are more reactive centers in chemical species. The Fukui function is a local reactivity descriptor that indicates the propensity of 
the electronic density to deform a given atomic site upon accepting or donating electrons (MendozaHuizar \& Rios-Reyes 2011; Komorowski et al. 2011). Further, with the help of these functions, local softness $\left(s_{k}^{+}, s_{k}^{-}, s_{k}^{o}\right)$ and local electrophilicity indices $\left(\omega_{k}^{+}, \omega_{k}^{-}, \omega_{k}^{o}\right)$ have been calculated using the equations $(6-10)$ and listed in the Table 3.

$f_{k}^{+}=\mathrm{q}_{\mathrm{k}}(\mathrm{N}+1)-\mathrm{q}_{\mathrm{k}}(\mathrm{N})$ for nucleophilic attack.
$f_{k}^{-}=\mathrm{q}_{\mathrm{k}}(\mathrm{N})-\mathrm{q}_{\mathrm{k}}(\mathrm{N}-1)$ for electrophilic attack $f_{k}^{o}=\mathrm{q}_{\mathrm{k}}(\mathrm{N}+1)-\mathrm{q}_{\mathrm{k}}(\mathrm{N}-1)$ for radical attack where $\mathrm{q}$ is the gross charge of atom $\mathrm{k}$.

$$
\begin{aligned}
& s_{k}^{+}=\mathrm{S} f_{k}^{+}, s_{k}^{-}=\mathrm{S} f_{k}^{-} \text {and } s_{k}^{o}=\mathrm{S} f_{k}^{o} \\
& \omega_{k}^{+}=\omega f_{k}^{+}, \omega_{k}^{-}=\omega f_{k}^{-} \text {and } \omega_{k}^{0}=\omega f_{k}^{o}
\end{aligned}
$$

Table 3. Hirshfeld atomic charges (in e.s.u.), Fukui functions $\left(f_{k}^{+}, f_{k}^{-}, f_{k}^{o}\right)$; Local softness $\left(s_{k}^{+}, s_{k}^{-}, s_{k}^{o}\right)$; and local electrophilicity indices $\left(\omega_{k}^{+}, \omega_{k}^{-}, \omega_{k}^{o}\right)$; in $\mathrm{eV}$ for atomic sites of AA I, using Hirshfeld

\begin{tabular}{|c|c|c|c|c|c|c|c|c|c|c|c|}
\hline \multirow[t]{2}{*}{ Atom no. } & \multicolumn{3}{|c|}{ Hirshfeld atomic charges } & \multicolumn{3}{|c|}{ Fukui functions } & \multicolumn{3}{|c|}{ Local softness } & \multicolumn{2}{|c|}{ Local electrophilicity indices } \\
\hline & $\mathrm{q}_{\mathrm{N}}$ & $\mathrm{q}_{\mathrm{N}+1}$ & $\mathrm{q}_{\mathrm{N}-1}$ & $f_{k}^{+}$ & $f_{k}^{-}$ & $f_{k}^{o}$ & $s_{k}^{+}$ & $s_{k}^{-}$ & $s_{k}^{o}$ & $\omega_{k}^{+}$ & $\omega_{k}^{-}$ \\
\hline $\mathrm{O} 1$ & $\begin{array}{l}- \\
0.1192\end{array}$ & $-\overline{0.0838}$ & $\begin{array}{l}- \\
0.1462\end{array}$ & 0.0354 & 0.0270 & 0.0624 & 0.0101 & 0.0076 & 0.0177 & 0.1993 & 0.1517 \\
\hline $\mathrm{O} 2$ & $\begin{array}{l}- \\
0.1409\end{array}$ & - & $\begin{array}{l}- \\
0.1722\end{array}$ & 0.0579 & 0.0313 & 0.0892 & 0.0164 & 0.0089 & 0.0253 & 0.3257 & 0.1760 \\
\hline $\mathrm{O} 3$ & $\begin{array}{l}- \\
0.1175\end{array}$ & $\begin{array}{l}- \\
0.0823\end{array}$ & $\begin{array}{l}- \\
0.1358\end{array}$ & 0.0352 & 0.0183 & 0.0535 & 0.0100 & 0.0052 & 0.0152 & 0.1982 & 0.1029 \\
\hline $\mathrm{O} 4$ & 0.0131 & 0.0502 & $\begin{array}{l}- \\
0.0242\end{array}$ & 0.0371 & 0.0373 & 0.0744 & 0.0105 & 0.0106 & 0.0211 & 0.2086 & 0.2100 \\
\hline $\mathrm{O} 5$ & $\begin{array}{l}- \\
0.2850\end{array}$ & $\begin{array}{l}- \\
0.2550\end{array}$ & $\begin{array}{l}- \\
0.3131\end{array}$ & 0.0300 & 0.0281 & 0.0581 & 0.0085 & 0.0080 & 0.0165 & 0.1687 & 0.1583 \\
\hline O6 & $\begin{array}{l}- \\
0.1989\end{array}$ & $\overline{-} .1580$ & $\overline{-} \mathbf{0 . 2 8 1 0}$ & 0.0409 & 0.0821 & 0.1230 & 0.0116 & 0.0233 & 0.0349 & 0.2302 & 0.4620 \\
\hline O7 & $-\overline{0.2130}$ & $\begin{array}{l}- \\
0.1809\end{array}$ & $\begin{array}{l}- \\
0.2920\end{array}$ & 0.0322 & 0.0790 & 0.1111 & 0.0091 & 0.0224 & 0.0315 & 0.1810 & 0.4443 \\
\hline N8 & 0.2617 & 0.2675 & 0.2225 & 0.0059 & 0.0391 & 0.0450 & 0.0017 & 0.0111 & 0.0128 & 0.0331 & 0.2200 \\
\hline C9 & 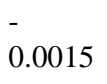 & 0.0088 & 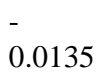 & 0.0103 & 0.0119 & 0.0223 & 0.0029 & 0.0034 & 0.0063 & 0.0581 & 0.0672 \\
\hline $\mathrm{C} 10$ & 0.0006 & 0.0253 & $\begin{array}{l}- \\
0.0016\end{array}$ & 0.0246 & 0.0023 & 0.0269 & 0.0070 & 0.0006 & 0.0076 & 0.1386 & 0.0127 \\
\hline $\mathrm{C} 11$ & 0.0070 & 0.0180 & $\begin{array}{l}- \\
0.0299\end{array}$ & 0.0110 & 0.0369 & 0.0479 & 0.0031 & 0.0105 & 0.0136 & 0.0617 & 0.2077 \\
\hline $\mathrm{C} 12$ & 0.0654 & 0.0967 & 0.0341 & 0.0313 & 0.0313 & 0.0626 & 0.0089 & 0.0089 & 0.0178 & 0.1759 & 0.1762 \\
\hline $\mathrm{C} 13$ & $\overline{-}-0124$ & 0.0139 & $-\overline{0.0345}$ & 0.0263 & 0.0221 & 0.0484 & 0.0075 & 0.0063 & 0.0137 & 0.1480 & 0.1242 \\
\hline $\mathrm{C} 14$ & 0.0246 & 0.0647 & $-\overline{0.0152}$ & 0.0401 & 0.0398 & 0.0799 & 0.0114 & 0.0113 & 0.0227 & 0.2258 & 0.2239 \\
\hline $\mathrm{C} 15$ & $-\overline{0.0183}$ & 0.0286 & $\begin{array}{l}- \\
0.0485\end{array}$ & 0.0469 & 0.0301 & 0.0771 & 0.0133 & 0.0085 & 0.0219 & 0.2641 & 0.1695 \\
\hline $\mathrm{C} 16$ & 0.0558 & 0.1078 & 0.0269 & 0.0521 & 0.0288 & 0.0809 & 0.0148 & 0.0082 & 0.0229 & 0.2928 & 0.1622 \\
\hline
\end{tabular}
population analysis at B3LYP/6-311++G(d,p) level. 


\begin{tabular}{|c|c|c|c|c|c|c|c|c|c|c|c|}
\hline C17 & 0.0208 & 0.0842 & 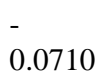 & 0.0633 & 0.0919 & 0.1552 & 0.0180 & 0.0261 & 0.0440 & 0.3564 & 0.5168 \\
\hline C18 & 0.0206 & 0.0718 & $\begin{array}{l}- \\
0.0466\end{array}$ & 0.0512 & 0.0672 & 0.1184 & 0.0145 & 0.0191 & 0.0336 & 0.2881 & 0.3780 \\
\hline C19 & 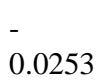 & 0.0281 & $\begin{array}{l}- \\
0.0579\end{array}$ & 0.0534 & 0.0326 & 0.0860 & 0.0152 & 0.0092 & 0.0244 & 0.3007 & 0.1832 \\
\hline $\mathrm{C} 20$ & 0.0860 & 0.1231 & 0.0621 & 0.0370 & 0.0239 & 0.0610 & 0.0105 & 0.0068 & 0.0173 & 0.2083 & 0.1347 \\
\hline $\mathrm{C} 21$ & 0.2332 & 0.3091 & 0.1915 & 0.0759 & 0.0417 & 0.1176 & 0.0215 & 0.0118 & 0.0333 & 0.4269 & 0.2345 \\
\hline $\mathrm{C} 22$ & 0.0145 & 0.0925 & $\overline{0}-0768$ & 0.0780 & 0.0912 & 0.1692 & 0.0221 & 0.0259 & 0.0480 & 0.4390 & 0.5132 \\
\hline $\mathrm{C} 23$ & $\overline{0}-0245$ & 0.0290 & $-\overline{0.0828}$ & 0.0535 & 0.0582 & 0.1118 & 0.0152 & 0.0165 & 0.0317 & 0.3011 & 0.3276 \\
\hline $\mathrm{C} 24$ & 0.2070 & 0.2168 & 0.2009 & 0.0098 & 0.0060 & 0.0158 & 0.0028 & 0.0017 & 0.0045 & 0.0551 & 0.0340 \\
\hline $\mathrm{C} 25$ & 0.1466 & 0.2071 & 0.1044 & 0.0605 & 0.0422 & 0.1027 & 0.0172 & 0.0120 & 0.0291 & 0.3402 & 0.2375 \\
\hline
\end{tabular}

From the Table, the oxygen atoms $\mathrm{O} 2$ (at five member ring), O4 (at carboxyl group) and the carbon atoms C17, C21, C22 (in rings) and C25 (at methoxy group) have suitable high potential for nucleophilic attack and where $s_{k}^{+}$and $\omega_{k}^{+}$values are maximum. Similarly, oxygen atoms $\mathrm{O} 6$ and $\mathrm{O} 7$ of nitro group and, carbon atom $\mathrm{C} 17$ in the ring are prone to the electrophilic attack where $s_{k}^{-}$and $\omega_{k}^{-}$ values are maximum. Therefore, it can be noticed that the nitro groups are more reactive in comparison to the methoxy and carboxyl group.

Molar refractivity: MR is important property used in quantitative structure property relationship. It reflects arrangements of the electron shells of ions in molecules and yields information about their electronic polarization. It relates the refractive index, molecular weight and the density, and is accomplished by a change in properties of ions under the influence of electric fields of the neighbouring ions. The molar refractivity (R; $\mathrm{cm}^{3} \mathrm{~mol}^{-1}$ ) is given by Lorentz-Lorentz (Padrón et al. 2002, Verma et al. 2005) expression:

$\mathrm{R}=\pi\left[\frac{n^{2}-1}{n^{2}+2}\right]\left[\frac{M}{\rho}\right]=\frac{4}{3} \pi \mathrm{N}_{\mathrm{A}} \alpha$

where $\mathrm{n}$ is refractive index, $\mathrm{M}$ is the molar mass, $\rho$ is the density, $\alpha$ electronic polarizability and $\mathrm{N}_{\mathrm{A}}$ the Avogadro's constant.

Thus the molar refractivity measures the polarizability of the ions i.e., the displacement of the electronic shell/s with respect to its nucleus. The above equation holds for both the liquid and solid state of the system. The value of $R$ depends upon the wavelength of the light used to measure the refractive index. For radiation of infinite wavelength it represents the real volume of the molecular system. The molar refractivity, which is responsible for the binding property of the title molecule with different amino acids, was calculated to be 49.8163 units.

\section{NON LINEAR OPTICAL (NLO) PROPERTIES}

NLO deals with the interaction of materials in the presence of applied electromagnetic field, which changes the wave number, phase and the other physical properties (Shen 1984). In presence of an applied electric field, the energy of a system is a function of the field. In recent years, the NLO phenomena have attracted much attention because of their potential applications in optical communication, optical sensing, data storage, computing etc (Zhang et al. 2002; Zhang et al. 2007; Kolev et al. 2008). The first hyperpolarizability $\left(\beta_{o}\right)$ of the molecular system, and the related properties polarizability $\left(\left|\alpha_{o}\right|\right)$ and anisotropy of polarizability $(\Delta \alpha)$ have been calculated using $6-311++\mathrm{G}(\mathrm{d}, \mathrm{p})$ basis set. First order hyperpolarizability is a third rank tensor that can be described by $3 \times 3 \times 3$ matrix. The 27 components of 3d-matrix can be reduced to 10 components by Kleinman symmetry (Kleinman 1962). The hyperpolarizability $(\beta)$ can be defined as the coefficients of Taylor series expansion of the energy expansion in the external electric field. 
During the weak and homogeneous electric field the expression becomes:

$$
\begin{aligned}
& E=E_{o}-\sum_{i} \mu_{i} F^{i}-\frac{1}{2} \sum_{i j} \alpha_{i j} F^{i} F^{j}- \\
& \text { 16ijkBijkFiFjFk..... }
\end{aligned}
$$

where, $E_{o}$ is the energy of unperturbed molecule, $F^{i}$ is the field at the origin $\mu_{i}, \alpha_{i j}$ and $\beta_{i j k}$ are the components of dipole moment, polarizability and first hyperpolarizability, respectively. The components of hyperpolarizability tensor are listed in the Table 4.

The total static dipole moment $\left(\mu_{o}\right)$, mean polarizability $(\Delta \alpha)$, anisotropy of polarizability $\left(\left|\alpha_{o}\right|\right)$ and first hyperpolarizability $\left(\beta_{o}\right)$ can be expressed as [Karna et al. 1991]:

$$
\begin{aligned}
& \mu_{o}=\left(\mu_{x}^{2}+\mu_{y}^{2}+\mu_{z}^{2}\right)^{1 / 2} \\
& \left|\alpha_{o}\right|=\frac{1}{3}\left(\alpha_{x x}+\alpha_{y y}+\alpha_{z z}\right) \\
& \Delta \alpha=\frac{1}{2}\left[\left(\alpha_{x x}-\alpha_{y y}\right)^{2}+\left(\alpha_{y y}-\alpha_{z z}\right)^{2}+\right. \\
& \alpha z z-\alpha x x 2+6 \mu x x 212 \\
& \beta_{o}=\left[\left(\beta_{x x x}+\beta_{x y y}+\beta_{x z z}\right)^{2}+\left(\beta_{y y y}+\beta_{x x y}+\right.\right. \\
& \left.\left.\beta_{y z z}\right)^{2}+\left(\beta_{z z z}+\beta_{x x z}+\beta_{y y z}\right)^{2}\right]^{1 / 2}
\end{aligned}
$$

\begin{tabular}{|c|c|c|c|c|c|c|c|c|}
\hline \multicolumn{3}{|c|}{ Dipole moment } & \multicolumn{3}{|c|}{ Polarizability } & \multicolumn{3}{|c|}{ Hyperpolarizability } \\
\hline & DFT & $\mathrm{HF}$ & & DFT & $\mathrm{HF}$ & & DFT & $\mathrm{HF}$ \\
\hline$\mu_{x}$ & -3.1124 & -3.0788 & $\alpha_{x x}$ & -107.6370 & -106.5696 & $\beta_{x x x}$ & -104.1119 & -96.8022 \\
\hline$\mu_{y}$ & 6.5909 & 6.4846 & $\alpha_{y y}$ & -143.6665 & -144.8090 & $\beta_{y y y}$ & 121.0077 & 118.4245 \\
\hline$\mu_{z}$ & 0.0154 & 0.0949 & $\alpha_{z z}$ & -148.4044 & -149.9088 & $\beta_{z z z}$ & 3.8081 & 4.2826 \\
\hline \multirow[t]{8}{*}{$\mu_{0}$} & 7.28884 & 7.17900 & $\alpha_{x y}$ & 4.0978 & 3.0428 & $\beta_{x y y}$ & 28.6413 & 25.6489 \\
\hline & & & $\alpha_{x z}$ & -1.2982 & -1.1461 & $\beta_{x x y}$ & -45.5336 & -48.1363 \\
\hline & & & $\alpha_{y z}$ & 2.7365 & 2.5102 & $\beta_{x x z}$ & -19.9328 & -19.5949 \\
\hline & & & $\left|\alpha_{0}\right|$ & 19.7589 & 19.8236 & $\beta_{x z z}$ & 6.0327 & 6.1301 \\
\hline & & & $\Delta \alpha$ & 21.2375 & 19.8152 & $\beta_{y z z}$ & 4.1590 & 4.3517 \\
\hline & & & & & & $\beta_{y y z}$ & 4.8116 & 6.6062 \\
\hline & & & & & & $\beta_{x y z}$ & 13.2848 & 13.3827 \\
\hline & & & & & & $\beta_{0}$ & 10.7805 & 8.6044 \\
\hline
\end{tabular}

Table 4. Dipolemoment ( $\mu$; Debye ), polarizability $\left(\alpha \times 10^{-24} \mathrm{esu}\right)$ and first hyperpolarizability $\left(\beta_{0} \times 10^{-31}\right.$ e.s.u.) calculated by using 6-311++ G(d,p) method.

As $\mathrm{x}, \mathrm{y}, \mathrm{z}$ components of $\left|\alpha_{o}\right|$ and $\beta_{o}$ obtained from Gaussian 09 output are in atomic unit (a.u.), the values were converted into electrostatic units (e.s.u.) using conversion factors (for $\left|\alpha_{o}\right|$ : 1 a.u. $=$ $0.1482 \times 10^{-24} \mathrm{esu}$; for $\beta_{o}: 1$ a.u. $=0.0086393 \times 10^{-30}$ e.s.u.) and listed in the Table 4. Urea is one of the molecules which have the good non linear optical property and it is used as a critical parameter for comparative studies $(\mu=1.3732$ Debye and $\beta=$ $3.7289 \times 10^{-31} \mathrm{~cm}^{5} /$ e.s.u.). For the title compound the first order hyperpolarizability by B3LYP/6$31++\mathrm{G}(\mathrm{d}, \mathrm{p})$ method is $10.7805 \times 10^{-31} \mathrm{~cm}^{5} /$ e.s.u. which is about three times more than that of urea, while by $\mathrm{HF} / 6-31++\mathrm{G}(\mathrm{d}, \mathrm{p})$ the first order hyperpolarizability is $8.6044 \times 10^{-31} \mathrm{~cm}^{5} /$ e.s.u., which is about two times more than that of urea.
Hence, the compound under study has a good non linear property.

\section{CONCLUSION}

The chemical reactivity, molecular electrostatic potential surface (MEP) and the non linear optical properties of molecule AA I have been calculated using DFT employing 6-311++G(d,p) basis set. The calculated local electrophilicity indices show that the oxygen atoms $\mathrm{O} 2, \mathrm{O} 4$ and the carbon atoms $\mathrm{C} 21, \mathrm{C} 22$ and $\mathrm{C} 25$ are prone to the nucleophilic attack. But the oxygen atoms O6 and $\mathrm{O} 7$ at the nitro group and the carbon atom C17 suitable for the electrophilic attack. The carboxyl group is more reactive than the methoxy 
group and less reactive than the nitro group. The value of dipole moment is $7.5888 \mathrm{D}$ and the first order hyperbolarizability obtained by DFT/HF about $3 / 2$ times higher than of urea show the strong non linear optical property of the molecule.

\section{ACKNOWLEDGEMENTS}

This work has been supported by the Brazilian National Council for Scientific and Technological Development $(\mathrm{CNPq})$ and TWAS, the academy of sciences for the developing world (CNPqTWAS/Post-Doc fellowship -2014).

\section{REFERENCES}

Attaluri, S., Bonala, R. R., Yang, I-Y., Lukin, M. A., Wen, Y., Grollman, A. P. et al. 2010. DNA adducts of aristolochic acid II: total synthesis and site-specific mutagenesis studies in mammalian cells. Nucleic Acids Research 38(1): 339-352.

Balachandran, P., Wei, F., Lin, R-C., Khan, I. A. and Pasco, D. S. 2005. Structure activity relationships of aristolochic acid analogues: Toxicity in cultured renal epithelial cells. Kidney International 67(5): 1797-1805.

Becke, A. D. 1993. Density-functional thermochemistry. III. The role of exact exchange. Journal of Chemical Physics 98: 5648-5652.

Bensky, D., Gamble, A., Kaptchuk, T. and Bensky, L. L. 1993. Chinese Herbal Medicine: Materia Medica, (revised ed.). Eastland Press Washington, USA, pp.136.

Chamers, J. M. and Griffiths P. R. (Eds.). 2002. Handbook of Vibrational Spectroscopy. John Wiley and Sons. ISBN: 978-0-471-98847-2.

Chattaraj, P. K. and Giri, S. 2007. Stability, Reactivity, and Aromaticity of Compounds of a Multivalent Superatom. The Journal of Physical Chemistry A 111(43): 1111611121.

Chidangil, S., Shukla, M. K. and Mishra, P. C. 1998. A Molecular Electrostatic Potential Mapping Study of Some Fluoroquinolone Anti-Bacterial Agents. Journal of Molecular Modeling 4: 250-258.

Cosyns, J. P. 2003. Aristolochic acid and 'Chinese herbs nephropathy': a review of the evidence to date. Drug Safety 26(1): 33-48.
Cronin, A. J., Maidment, G., Cook, T., Kite, G. C., Simmonds, M. S., Pusey, C. D. et al. 2002. Aristolochic acid as a causative factor in a case of Chinese herbal nephropathy. Nephrology Dialysis Transplantion 17: 524-525.

Das, T. S. 2016. Evaluation of Aristolochia bracteolata Linn. For antimicrobial activity, alpha-glucosidase inhibition and its phytochemical constituents. Ashian Journal of Pharmaceutical and Clinical Research 9(1): 137-142.

Frisch, M. J., et al. 2009. GAUSSIAN 09, Revision, Gaussian Inc. Wallingford, CT.

Geerlings, P., De Proft, F. and Langenaeker, W. 2003. Conceptual density functional theory. Chemical Review 103(5): 1793-1873.

Hohenberg, P. and Kohn, W. 1964. Inhomogeneous Electron Gas, Physical Review B 136: 864871.

Joshi, B. D., Mishra, R., Tandon, P., Oliveira, A. C. and Ayala, A. P. 2014. Quantum chemical studies of structural, vibrational, NBO and hyperpolarizability of ondansetron hydrochloride. Journal of Molecular Structure 1058: $31-40$.

Joshi, B. D., Srivastava, A., Gupta, V., Tandon, P. and Jain, S. 2013. Spectroscopic and quantum chemical study of an alkaloid aristolochic acid I. Spectrochimica Acta Part A: Molecular and Biomolecular Spectroscopy 116: 258-269.

Karna, S. P., Prasad, P. N. and Dupuis, M. 1991. Nonlinear optical properties of $p$-nitroaniline: An ab-initio timedependent coupled perturbed Hartree-Fock study. The Journal of Chemical Physics 94(2): 1171-1181.

Kleinman, D. A. 1962. Nonlinear Dielectric Polarization in Optical Media. Physics Review 126: 1977-1979.

Kolev, T. M., Yancheva, D. Y., Stamboliyska, B. A., Dimitrov, M. D. and Wortmann, R. 2008. Nonlinear optical properties of pyridinium-betaines of squaric acid: Experimental and theoretical study. Chemical Physics 348: 45-52.

Komorowski, L., Lipiński, J., Szarek, P. and Ordon, P. 2011. Polarization justified Fukui functions: The theory and applications for 
molecules. The Journal of Chemical Physics 135(1): 014109-1-014109.

Kupchan, S. M. and Doscoth, R. W. 1962. Tumor inhibitors. I. Aristolochic acid, the active principle of aristolochia indica. Journal of medicinal and pharmaceutical chemistry 5: 657-659.

Lee, C. T., Yang, W. and Parr, R. G. 1988. "Development of the Colle-Salvetti correlation-energy formula into a functional of the electron density". Physical Review B 37(2): 785-789.

Li, X., Yang, L. and Yu, Y. 2001. An analysis of the clinical and pathological characteristics of mu-tong (a Chinese herb) induced tubulointerstitial nephropathy. Zhonghua Nei Ke Za Zhi 40: 681-687.

Mendoza-Huizar, L. H. and Rios-Reyes, C. H. 2011. Chemical Reactivity of Atrazine Employing the Fukui Function. Journal of Mexican Chemical Society 55(3): 142-147.

Mishra, R, Joshi, B. D., Srivastava, A., Tandon, P. and Jain, S. 2014. Quantum chemical and experimental studies on the structure and vibrational spectra of an alkaloid Corlumine. Spectrochimica Acta Part A: Molecular and Biomolecular Spectroscopy 118: $470-480$.

Mizuno, M., Oka, T., Yamamoto, H., Iinuma, M. and Murata, H. 1991. Comparison of Aristolochia Species with Chemical Constituents. Chemical and Pharmaceutical Bulletin 39(5): 1310-1311.

Padrón, J. A., Carasco, R. and Pellón, R. F. 2002. Molecular descriptor based on a molar refractivity partition using Randic-type graph-theoretical invariant. Journal of Pharmacy \& Pharmaceutical Sciences 5(3): 258-266.

Pailer, M. L., Belohlav, L. and Simonitsch, E. 1995. Zur konstitition der Aristilochiasauren. Monatshefte für Chemie 86: 676-680.

Parr, R. G. and Yang, W. 1989. Density Functional Theory of Atoms and Molecules. Oxford University Press, New York. Oxford, pp 333.

Parr, R. G., Szentpály, L. and Liu, S. 1999. Electrophilicity Index. Journal of the American Chemical Society 121(9): 19221924.
Perdew, J. P. and Wang, Y. 1992. Accurate and simple analytic representation of the electron-gas correlation energy. Physics Review B 45(23): 13244-13249.

Rosenmund, H. and Reichstein, T. 1943. Zur Kenntnis Aristolochiasaure. Pharmceutica Acta Helvetiae 18: 243-261.

Shen, Y. R. 1984. The Principles of Nonlinear Optics. John Wiley \& Sons, New York, pp 576.

Tang, W. and Eisenbrand, G. 1992. Chinese Drugs of Plant Origin-chemistry, Pharmacology and Use in Traditional and Modern Medicine. Springer-Verlag, Berlin, Germany, pp145.

Thirugnanasampandan, R., Mahendran, G. and Narmatha Bai, V. 2008. Antioxidant properties of some medicinal Aristolochiaceae species. African Journal of Biotechnology 7(4): 357-361.

Verma, R. P., Kurup, A. and Hansch, C. 2005. On the role of polarizability in QSAR. Bioorganic \& Medical Chemistry 13(1): 237-255.

Zhang, C., Song, Y., Kühn, F. E., Wang, Y., Fun, H., and Xin, X. 2002. Study on a series of pentanuclear planar 'open' clusters: synthesis, characterization, strong third-order optical nonlinearities and superior optical limiting properties. Journal of Material Chemistry 12(2): 239-248.

Zhang, C., Song, Y. L. and Wang, X. 2007. Correlations between molecular structures and third-order non-linear optical functions of heterothiometallic clusters: A comparative study. Coordinaton Chemistry Reviews 251(1-2): 111-141.

Zheng, F., Wen, X., Li, X., Gao, R. and Zhang, X. 2000. Synergistic effect of monocyte chemotactic protein-1 and aristolochic acid I on transdifferentiation of human tubular epithelial cells in vitro. Zhonghua Nei $\mathrm{Ke} \mathrm{Za}$ Zhi 39: 831-834.

Zhurko, G. A. and Zhurko, D. A. 2005. CHEMCRAFT, < www.chemcraftprog.com〉. 